\title{
XLVI. Attempts to detect the production of helium from the primary radio-elements
}

\section{Frederick Soddy M.A.}

To cite this article: Frederick Soddy M.A. (1908) XLVI. Attempts to detect the production of helium from the primary radio-elements, Philosophical Magazine Series 6, 16:94, 513-530, DOI: $10.1080 / 14786441008636535$

To link to this article: http://dx.doi.org/10.1080/14786441008636535

册 Published online: 21 Apr 2009.

Submit your article to this journal $\widetilde{x}$

Џ Article views: 6

Q View related articles $\square$

Citing articles: 1 View citing articles 5 
XLVI. Attempts to detect the Prollection of Helium from the Primary Radio-Jlements. By Frederick Sovdr, M.A.*

[Plate XX.]

THE question whether helium is a product of the radioL active changes of uranium and thorium has proved an extremely difficalt one to settle experimentally. The work here described was commenced in 1905, and the results obtained, though by themselves of no significance as yet, appear to warrant the hope that all difficulties have been overcome, and now only a sufficiently long period of time and periodic testing are required to solve the problem. The quantities of helium that have been looked for throughout are of the order of a millionth part of a cubic centimetre, which is the amount present in only a fraction of a cubic centimetre of atmospheric air. From the first it was recognized that the difficulties in the way of ensuring that the observations had a real significance were so formidable, that mere qualitative detection or non-detection of helium, however detinite or frequently repeated, would not of itself suffice to settle the question beyond all doubt. The objects of the experiments have been to obtain a quantitative estimate by the spectroscope of the amount of helium produced from uranium and thorium, or in the event of negative results to fix a definite limit to the quantity of helium that could not fail to have been detected under the conditions. To be quite sure, it is necessary to carry out a long series of consistent quantitative experiments, in which helium is detected with regularity when the time of accumulation is above, and not detected when the time of accumulation is below a certain period. These are only now being commenced. Whether the necessary certainty and perfection have been achieved for the results to bear a significant interpretation, only the results of future tests will disclose. All that can now be claimed is that a beginning has been made.

\section{Theoretical Rate of Production of Helium.}

At the commencement of the work radioactive theory afforded only a halting and as it now seems deceptive guide to the order of the amount of helium to be looked for in experiments of this character. The calculations were so indirect and so imperfect that it was hardly possible to say as the result of any given experiment that it definitely conflicted with what is theoretically to be expected. The

* Communicated by the Author.

Plicl. Mag. S. 6. Vol. 16. No. 94. Oct. 1908. 
theoretical estimates formed from now available data are quite different from what were formed when the work was commenced, and the difference betwern the older and the newer estimates indicated by theory have steadily widened as the new data have been accumulated. Had the present data been available, the task would have appeared even more hopeless to attempt than it did at first, for the theoretical estimates of the rate of disintegration of the primary radioelements have steadily decreased. Thus Professor Rutherford gave for the radioactive constant of uranium, in 1905, $10^{-9}$ (year) ${ }^{-1}$ ('Radioactivity,' 2nd edition, p. 458), and in $19062 \times 10^{-10}$ (year) $^{-1}$ ('Radioactive 'Transformations,' p. 158), while the present value, calculated by the same method as the last, from more recent data, has again been lowered to $1.2 \times 10^{-10}$. Considering the nature of the quantity, the alteration does not appear very vital, but for the purposes of the present work the difference between the first and last value is just the difference between waiting six weeks and waiting a year between tests before sufficient helium to be detected accumulates. The first is practicable, the second is hardly so.

While, however, the quantitative estimates of the rate of production of helium bave decreased, the general progress of radioactivity since the commencement of the work has increased the probability that helinm is a product of uranium and thorium, and indeed of all radio-elements producing a-rays, to such an extent that it is difficult at the present time to maintain the opposite view. The chief evidence, of course, is derived from the elucidation of the nature of the $\alpha$-rays by Rutherford; but strong support is also given by the way in which the atomic weights of uranium, radium, and polonium, the latter estimated from its probable position in the periodic table, conform to the simple supposition that each a-ray-producing change results in a reduction of the atomic weight by four units.

It would scarcely be profitable to discuss all the possibilities that have to be taken into consideration in attempting to arrive at the upper and lower limits of the rate of produetion of helium indicated by theory. It is better to make the most probable assumptions and to consider in which dircetion the rate would be affected if these assumptions are altered.

The value $1.2 \times 10^{-10}$ (year) ${ }^{-1}$, just referred to, is arrived at by the application of the disintegration theory in its simplest form, from the ratio of the quantities of uranium to radium in minerals and the rate of disintegration of radium. 
Throughout the most recent value for the latter, $3.48 \times 10^{-4}$ (year)-1, given by Boltwood (Am. Journ. Sci., June 1908, p. 493), will be taken. Multiplying it by the most recent value $\left(3 \cdot 4 \times 10^{-7}\right)$ for the ratio of radium to uranium in minerals (Boltwood, loc. cit. April 1908, p. 297), gives $1.2 \times 10^{-10}$ (year) $^{-1}$, which may be taken as the present theoretical value for the rate of disintegration of uranium according to these data, and will be referred to as the "direct value." For thorium we have yet no such direct method, and the difficulties commence.

It is necessary, before any further progress can be made with the calculation, to introduce the assumption that the $\alpha$-particle is an atom of helium, and to first deduce, from the rate of disintegration of uranium, the rate of production of helium, on the assumption that one atom of uranium gives rise to some definite number $(\mathrm{N})$ of atoms of helium. As the $\alpha$-radiation of uranium is apparently homogeneous, and produced in the apparently single change of uranium into uranium $X$, it is reasonable to assume at first that one atom of helium is produced from one atom of uranium, and therefore that the helium is one-sixtieth of the weight of uranium disintegrating. This gives $2 \times 10^{-12}$ (year) ${ }^{-1}$ for the rate of production of belium from uranium.

To find from this the rate of production of helium from thorium it suffices, on the assumptions made, to compare the relative $\alpha$-radiation of uranium and thorium and the average velocities of the $\alpha$-particle of uranium and thorium respectively. For present purposes perhaps a sufficient approximation is reached if we regard the relatively greater average velocity of the thorium $\alpha$-particle as just compensating for the relatively higher specific $\alpha$-activity of thorium. This gives the same rate of production of helium for both uranium and thorium, viz. $2 \times 10^{-12}$ (year) ${ }^{-1}$.

The unfortunate feature about this calculation is that it may not be allowable to calculate the ratio of the rate of disintegration of radium to that of uranium, from the ratio of their respective quantities in minerals, because it is uncertain that the disintegration theory in its simplest form applies. Rutherford has suggested tentatively, in order to bring actinium into the scteme of radioactive changes in pitchblende, that actinium may be a product of disintegration of uranium produced simultaneously with the radium series, and not in the direct line between uranium and radium. If this is true, in equilibrium the number of atoms of radium formed are but a fraction of the atoms of uranium disintegrating, and the rate of disintegration of uranium must 
certainly be greater than $1.2 \times 10^{-10}$, but to an, at present, indeterminate extent. This direct value therefore may be unsound, and the error affects also the derived calculations for thorium. As about to be shown, the increase from this cause is not, unfortunately, likely to be very great.

There is also an indirect method of calculating the rate of production of helium by a comparison of the a-rays, for which Boltwood has just recently supplied much more complete data than were before available. It leads to a greater value than the direct method, which we have seen is likely to give too low a value, and is perhaps to be preferred. Boltwood deduces from his most recent determination of the proportionate $\alpha$-radiation contributed by each of the radioactive bodies in uranium minerals (Am. Journ. Sci., April 1908, p. 296) that the $\alpha$-activity of radium (free from all products) is 1,300,000 times that of uranium. As the range of the a-particle is the same in each case, the rate of disintegration of uranium by this method comes out at $3.48 \times 10^{-4} \div 1.3 \times 10^{6}=2.7 \times 10^{-10}$. This is 2.25 times the "direct value," and gives for the rate of production of helium from uranium and thorium $4.5 \times 10^{-12}$ (year) ${ }^{-1}$. For pitchblende, containing equilibrium amounts of all products, Boltwood (loc. cit.) finds the a-activity to be about 4.7 times that contributed by the uranium. As some of this activity is due to $\alpha$-rays of much higher velocity than those of uranium, one can deduce in this method of calculation that for pitchblende the rate of production of helium should be about four times that of the uranium it contains. Whereas, of course, on the simple disintegration theory, which recognizes in pitchblende the existence of seven, and indicates eight, $\alpha$-ray or helium-producing changes, only one of which is contributed by uranium, it is to be expected that pitchblende would produce helium at eight times the rate of the uranium present, which is twice the preceding value. Boltwood himself points out that the discrepancy could be partially accounted for on the assumption that uranium suffers two $\alpha$-ray changes, which is, according to the preceding view, that the uranium atom gives two helium atoms. Certainly his results are most suggestive. The a-radiation from the radium series is in good agreement with the riew that a single $\alpha$-particle is expelled by radium and by each of its successive a-ray products, the $\alpha$-radiation from uranium is slightly more than would be the case if it expelled two $\alpha$-particles, while the whole of the $\alpha$-ray-changes of the actinium series together only constitute about one-half the effect of a single $a$-ray change in the radium series. As 
there are four $\alpha$-ray changes known in the actinium series, these results indicate that out of eight atoms of uranium disintegrating, seven go to produce radium and one to produce actinium. With these assumptions the direct and indirect values for the rate of disintegration of uranium become consistent and give the same value $2 \cdot 7 \times 10^{-10}$ (year) ${ }^{-1}$. Thus $4 \cdot 5 \times 10^{-12}$ (year) ${ }^{-1}$ may be taken as the more probable value in both cases, while for pitchblende, assuming that all the helium formed comes into evidence as $\alpha$-rays, the more probable value is four times that of the uranium it contains. The smallest possible quantity of helium that can be detected under present conditions will be shown to be about a millionth of a cubic centimetre, or $1.8 \times 10^{-10} \mathrm{gram}$. That is to say, a gram of uranium or thorium should produce a just detectable amount of helium in a period of 40 years, while for a quantity of pitchblende containing a gram of uranium and all its products the same should occur in 10 years. Even with considerable quantities of material the accumulation of results must therefore be necessarily a slow process. So far it has not been practicable to deal with quantities of material containing more than a third of a kilogram of the element, so that on the new data it is to be expected that the minimum period of accumulation to give a positive result with uranium or thorium must be considerably over a month, on the indirect value, or three montis on the direct value.

In absence of direct experiments the question has been attacked indirectly, with conflicting conclusions by different observers, from the association of helium with uranium and thorium in minerals. Boltwood (Am. Journ. Sci. 1907, xxiii. p. 77) considers that helium is probably not a product of thorium disintegration, and that, even in thorianite, the helium can be accounted for by the disintegration of the uraninm series alone. This would of course involve the abandonment of the view that the $\alpha$-particle is an atom of helium and of almost all the preceding theoretical calculations. The only datum that would remain would be that from the "direct value" of the rate of disintegration of uranium, namely, that the helium production is $\mathrm{N} \times 2.10^{-12}$ (year) ${ }^{-1}$, where $\mathrm{N}$ is the number of atoms of helium formed from one atom of uranium, and this would be subject to an increase should branch series, such as actinium, occur. Strutt (compare Proc. Roy. Soc. 1908, 80 A, p. 572), on the other hand, has advocated the other view. He regards the existence of helium in a specimen of fluor from Ivitgut, Greenland, examined by Prot. Julius Thomson, which contains thorium 
and helium but no radium, as conclusive evidence that helium is a disintegration product of thorium. He finds from a recent examination of a large number of rare, and representative common minerals, that helium in detectable quantity is present in all. In every case but one it can be accounted for by the presence of the uranium-radium series and of thorium. The exception is Beryl, which contains noticeable amounts of helium and is scarcely radioactive. The existence of even this one exception would appear to weaken somewhat the argument he draws from the presence of helium in fluor, and shows the necessity for caution in drawing conclusions by the indirect method.

Sufficient has been said to show the deep importance of obtaining if possible a direct experimental determination of the rate of production of helium from the primary radioelements and from the radioactive minerals. There is little doubt that such results, if they can be obtained, would prove invaluable in settling some of the outstanding problems in radioactivity which radioactive methods from their nature are unable unaided to solve.

\section{Method of Work, and Early Eaperiments.}

The process recently described (Soddy, Proc. Roy. Soc. $1907,78 \mathrm{~A}$, p. 429) for the detection and measurement of infinitesimal quantities of helium has been exclusively used. It depends on the use of calcium heated to its volatilisation point in a specially constructed vacuum electric furnace. All known gases but those of the argon family are perectly absorbed. The completeness of the absorption under proper conditions is such that the residual gas compressed several thousand times (by filling the absorption vessel after cooling. with mercury) into the smallest possible spectrum-tube hardly suffices to conduct the discharge, and, in the absence of argon gases, the spectrum-tube remains on the verge of non-conductance. The sensitiveness of the method as a test for the presence of helium is increased many thousand times by filling the apparatus with mercury, although the labour of the investigations entailed in the continual cutting down and building up of the complex apparatus is of course very great. The general method throughout has been to store the substances under examination in solution in glass flasks placed on water-baths. The air is first as completely as possible removed by boiling the solutions and pumping with a mercury-pump through a U-tube placed in a freezingmixture. A new mercury-pump filled with new mercury, provided with two large drying-tubes, containing sulphuric 
acid and phosphorus pentoxide respectively, was erected at the commencement of the work, and has been kept exclusively for these experiments. In making a test for helium, the calcium furnace is first pumped out as completely as possible, the calcium is then heated, and the pumping continued, so that the expelled gas serves to wash out the last traces of air. The pump is then sealed off, and communication made with the flask through the cooled U-tube, and the solution boiled. The calcium furnace is sealed off and, when cold, filled in the dark room with dry mercury. As soon as the spectrum-tube conducts at all, the spectrum is rapidly examined with a Ramsay train of prisms, and if $\mathrm{D}_{3}$, the characteristic line of the helium, is observed, the tube is generally sealed off and examined with a good spectroscope.

The first and also the second series of experiments with thorium and uranium came to a premature end on account of accidents; but the third series, of which the experiment with thorium was started first, has been more successful, and is still in progress. The main experimental difficulty at first encountered was air. The argon in a few cubic centimetres of air is sufficient to prevent completely the detection of the minute amounts of helium looked for in these experiments. To free a litre or more of solution from every trace of air, and to preserve it for months or years in this condition while making provision for the complete removal of the gas for testing at will, calls for very perfect arrangements, and the method employed in the last series is the outcome of many previous failures. In the first series of experiments, started in August 1905, about a kilogram each of uranium nitrate and thorium nitrate, of ordinary commercial quality, were employed. The exit tube from the flasks was joined to a Y-tube, the vertical limb of which was a barometer dipping into a mercury reservoir which could be raised or lowered, sealing or opening the passage through the upper branches of the Y-tube. The other branch of the $\mathrm{Y}$ was provided with a tap, and the pump, \&c. could thus be sealed to it without air entering the solution. In this way the air-tightness of the tap was depended upon only during the actual removal of the gases to the testing-furnace, and any air leaking through during the long periods of accumulation could be removed before lowering the mercury seal. This worked well until one night the lubricant of the tap failed, and the next morning air was found to be bubbling through the mercury seal into the flasks. Before this ten tests had been madesix with the uranium and four with the thorium. The whole of six former and the first three of the latter were failures 
on account of the presence of argon, from air in the solutions. The last test with thorium was completely successful, but it was in the nature of a blank experiment, the period of accumulation of gas in the thorium being only about 22.5 hours. No sign of helium was seen. The ninimum quantity detectable under the circumstances-about $2 \times 10^{-9}$ gram-would have been observed, as the experiment was a very perfect one.

In the second series of experiments, vertical all-glass reflux condensers were sealed to the flasks, and the principle of the mercury seal was pushed to its logical conclusion by making the two upper limbs of the Y-tube the barometric height, so that there could be a vacuum on the one side and the pressure of an atmosphere on the other. The principle was correct, and is being used in the experiments now in progress; but the design was faulty, and the arrangement need not therefore be described in more detail. Four flasks were set up in this series, but only two, with the uranium and thorium preparations before employed, are concerned in this investigation. The first and the only test with the thorium solution failed on account of argon being present. Carbon dioxide was noticed in the gas as it was admitted to the furnace, and, after the absorption, the spectrum was that of pure argon. The first two tests with uranium failed also from the same cause, but the last was a perfect experiment. The solution had been left to accumulate for six days and four hours, and $\mathrm{D}_{3}$ was present faint and clear on the spark-spectrum of argon. The spectrum-tube was of soda glass with a volume of 0.3 c.c., a kind that has been subsequently abandoned. With it, a quantity of about $2 \times 10^{-9}$ gram helium could be detected.

During the experiment, however, a violent bumping of the uranium solution during boiling projected some of it over on to the top of the mercury in the tap, and the strongly acid liquid at once began to attack the mercury with the evolution of oxides of nitrogen. These, of course, did no harm, as the calcium absorbs them, but the flask had to be cut down. In this operation, owing to faulty design of the mercury taps, the whole of the flasks were spoiled, and this series of experiments came to an end. With regard to the single result, it must be borne in mind that the experiment was performed three years ago, before the possible sources of error were as well known as now, and no significance is to be attached to it. In fact, more recent results have failed to confirm it.

In the first experiment of the third series with thorium now 
in progress, many changes and improvements were introduced. So far as the flask and its attached mercury tap is concerned, the design then adopted has been adhered to with but slight modification in all the later experiments, and has been found to work perfectly, and will therefore be described in detail. But frequent changes have been made from time to time in the method of performing the testing operations. As finality in this direction has perhaps not even yet been reached, the detailed description of this part of the work will be deferred. The apparatus in its present form is shown in the diagram in fig. 1 (p. 522), and the photographs of the actual thorium apparatus, from the front and from the sides, are shown in Plate XX. The earlier failures had shown the difficulty, first of freeing a large quantity of liquid periectly from dissolved air, and secondly of getting it under these circumstances to boil regularly. The dangerous percussive boiling; which made the earlier experiments so precarious, was reduced, and at the same time the dissolved air was efficiently and rapidly removed by sealing into the flask (B) a tube reaching to the bottom and connected to a voltameter (A) for generating a mixture of hydrogen and oxygen. Au all-glass vertical condenser (C) with double circulation of water was sealed to the neck of the flask, and provided at the upper end with a large bulb. This was connected to a trap (D) formed by a single drop of mercury, for the purpose of preventing the expelled gas from diffusing back into the flask. During the preliminary remoral of the air the by-pass (x) was open, and then it was sealed as shown. $\mathrm{E}$ is a glass chamber for combining the hydrogen and oxygen by means of a discharge from a coil, and for condensing the bulk of the water produced. $\mathrm{F}$ is the mercury tap. $\mathrm{G}$ is the U-tube to condense watervapour, which in the later experiments has been immersed in liquid air. $H$ is the calcium furnace, which, after the experiment, is sealed off and filled with mercury from the crucible (L). $\quad \mathrm{K}$ is the spectrum-tube described later. $J$ is a subsidiary volume, only used in the more recent tests, the purpose of which is to neutralize the effect of the volume of the U-tube. The device is copied from that employed by Ramsay \& Cameron (Journ. Chem. Soc. Trans. 1907, p. 1598, fig. 1). The U-tube $G$ must necessarily have a somewhat large volume to prevent its becoming choked with ice. At the temperature of liquid air its volume is virtually trebled, whereas the volume of the calcium furnace at the high temperature is virtually halved. Hence an inconveniently large fraction of the gas remains in the U-tube when it is sealed off. To avoid this, $\mathcal{J}$ is surrounded with a cup of moist filter-paper 
which is then filled with liquid air. Its volume is equal to or greater than that of the U-tube, and hence the greater part of the gas is obtained for the test.

Fig. 1.

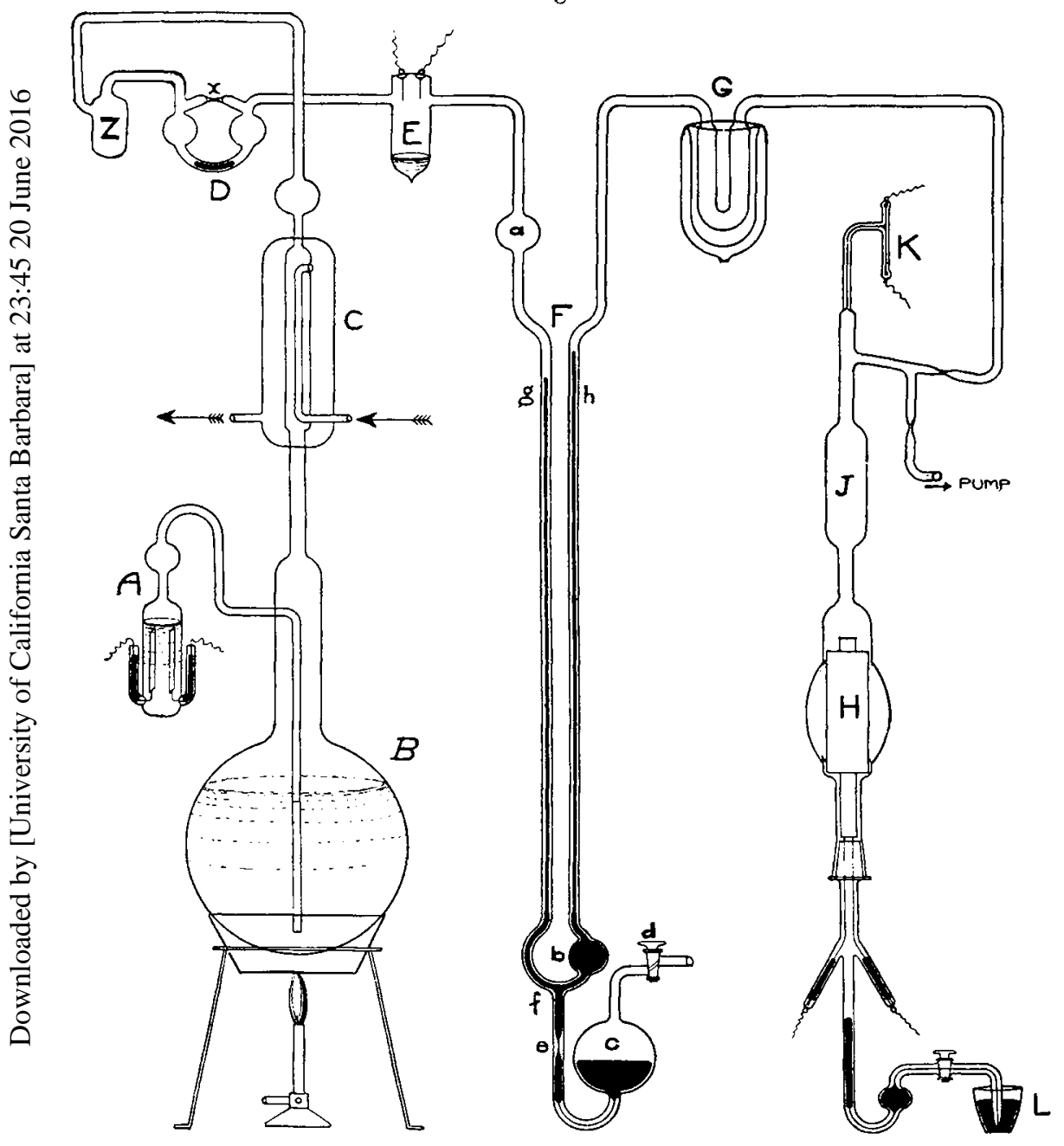

The procedure in removing air is simply to keep the solution boiling and to pass a rapid current of gas from the voltameter, recombining it with occasional sparks in the chamber E. From time to time, the mercury in the tap is 
lowered and the contents of $E$ removed by the pump. The $\operatorname{tap} \mathrm{F}$ alone calls for more detailed description. It is worked by connecting the tap $d$ to a mechanical air-pump. It is made slow-acting by means of the construction (e). Obviously the bulb (c) must be below the level of the junction of the limbs $(g)$ and $(h)$; so that if the tap $(d)$ were left open to the air when $h$ is also open to the air, the mercury would be blown out of the tap into the flask. This is the sole danger to guard against. If the tap $(d)$ is closed in time, even a sudden break anywhere on the $h$ side of the mercury tap does no harm. The small bulbs $a$ and $b$ take up the inertia of the moving mercury, and the slow flow of mercury into $c$ increases the pressure of the air there above the atmospheric so that the mercury remains in the tap permanently above the level $f$. The dimensions of the tap are as follows :-

Height over all, $107 \mathrm{cms}$.

Distance between the bulbs $a$ and $l, 85 \mathrm{cms}$.

Diameter of bulb c, $40 \mathrm{mms}$.

Diameter of barometer-tubes $g$ and $h, 3 \mathrm{mms}$.

Diameter of bulbs $a$ and $b, 26$ mms.

What is very important is that these dimensions have sufficient margin to allow of the slight excess of pressure required for glass-blowing operations on the $h$-limb of the tap while there is a vacuum in the other. It was the failure to allow for this contingency which caused the accident to the second series of experiments.

The height of the mercury in the limb $g$ indicates the pressure of gas in the flask, which is never allowed to exceed a few cms. of mercury. Soon after setting up the thorium and uranium flasks, some of the mercury in the trap D found its way into the solutions during the operations, contaminating them and causing oxides of nitrogen to be present in the removed gases. This does no great harm, but in the later experiments the trap $Z$ has been added to avoid this contingency. It is probable no further modification of this part of the apparatus will be called for.

What may be called the engineering of so unwieldy an apparatus may be seen from the Plate (XX.). On the small wood base supporting the water-bath is fixed a vertical bar of T-iron to which the flask, condenser, voltameter, and mercury tap are fastened. The voltameter is between the flask and mercury tap, and is not seen in the photographs except by reflexion in the circular mirror placed behind it. The apparatus, when sealed off from the furnace, is selfcontained, and can if necessary be moved. When not in use, 
the tube attached to the limb $h$ is exhausted and sealed. In reopening it, it is advisable to break the tip under a rubber cap and to admit the air slowly, although each mercury tin?, before being used, is tested under working conditions by a sudden break to ensure that it is correctly dimensioned. Recently such a sudden break occurred with the thorium flask, doing no harm.

\section{Spectroscopic Test for the presence of Helium.}

Before discussing the results so far obtained, it is necessary to state exactly what is and what is not considered sufficient evidence of the presence of these infinitesimal quantities of helium. The $D_{3}$ line is generally the only line visible, and fortunately its position is quite easy to verify with accuracy owing to its proximity to the sodium lines. The $\mathrm{D}_{3}$ line becomes quite brilliant under all circumstances before any of the other lines in the helium spectrum appear. Now the hydrogen secondary spectrum, which is composed of so many lines in the yellow and green region that it appears more or less continuous, has a line so near $\mathrm{D}_{3}$ that it cannot be distinguished by visual observation even with a good spectroscope. It is always less brilliant than other lines on the more refrangible side. An ordinary hydrogen tube, filled at not too low pressure, shows this line; and it is useless to attempt to detect the minimum amount of helium in presence of the hydrogen secondary spectrum. It is also useless when argon is at all strong, as there are lines in the spectrum very close to $\mathrm{D}_{3}$, although there is always more than one, relatively weak, in the small tubes ased, compared to the other lines. In the cases mentioned the test would be rejected. What is required is that $D_{3}$ should be seen on a black background with no lines in its immediate neighbourhood, except $D_{1}$ and $D_{2}$ if a soda-glass spectrum is used, and the position of the line must be exactly found both with reference to the sodium line, and by comparison with a helium-tube.

A considerable quantity of helium, say 10 or 20 times the minimum amount, can be detected in presence of a strong argon spectrum, as $\mathrm{D}_{3}$ under these circumstances is far brighter than the neighbouring argon lines. Very small quantities of argon do not interfere greatly with the observation of $\mathrm{D}_{3}$; for under these circumstances only the blue or spark spectrum of argon is observed, which bas practically no lines in the less refrangible part of the spectrum.

With the infinitesimal quantities of gas dealt with in these experiments, the passage of even a weak discharge causes the spectrum-tube to become non-conducting in a few 
seconds. All observations must be carried out very quickly, bat with experience a single glance is usually sufficient; and one's first judgment, even with the smallest quantities of helium, is rarely reversed by subsequent observations.

One other very important consideration must be mentioned. The fact that the argon from a cubic millimetre of air is sufficient to spoil the test is in reality a very great advantage, and constitutes its main claim to suitability and safety in the present work. If, for example, the method of Sir James Dewar, of absorbing non-helium gases by cold charcoal, were employed, since that method absorbs argon also, there never could be any complete certainty, when helium was observed, that it was not derived from atmospheric air which had been left in the solution, or had leaked in. With the method employed the slightest leak of air is fatal in itself, and there is no possibility if helium is observed that it is derived from the air. When first devised, it was thought the method would make the work comparatively easy; but afterwards, when the numerous failures due to residual argon were being experienced, it seemed as though little had been gained. In the work with radium the difficulty had been nitrogen; whereas here exactly the same precautions had to be taken to exclude air as if the calcium had not been able to absorb nitrogen. Its ability to absorb the hydrogen and hydrocarbon gases always normally present in work of this character, is, however, its real advantage.

\section{Calibration Experiments.}

Everything depends, if the results are to have any theoretical signiticance, upon the smallest amount of helium that can be detected by the method described being accurately and definitely known; and this part of the investigation has been carried out with great care. The results have been gratifying in that they have shown that the limit of visibility of the $\mathrm{D}_{3}$ line constitutes a perfectly sharp and definite quantitative test for helium. Some preliminary experiments on this question were given in the original paper describing the method. Ordinary Plücker tubes were employed and the apparitus was not filled with mercury, but the minimum quantity detectable was arrived at by dividing the total quantity added by the ratio of the total volume to that of the spectrum-tube employed. The present data show that there is an error somewhere in these calculations, owing probably to the limiting partial pressure of helinm detectable in an ordinary Plücker tube being less than in a tube of minimum volume. The minimum detectable quantity of helium, even in a tabe of the 
smallest possible volume, is much greater than was formerly deduced by calculation. Thus while the estimates of the amounts of helium to be expected have grown less, the estimates of the capabilities of the spectroscope have also diminished; so that the task is now known to be more difficult, for a double reason, than was at first supposed.

In the present series of tests the processes of sealing off, absorption, and subsequent filling of the apparatus with mercury, were carried out exactly as in actual experiments. Tests were conducted with three different types of spectrumtubes, all furnished with electrodes of simple platinum wire. Those used in the early work, but now abandoned, had a volume of about 0.3 c.c., and were made of soda-glass. The bore of the capillary was rather too wide for the best results. The kind now used exclusively consist of a very small tube indeed, with hardly any unnecessary space around the electrodes, made of lead-glass with a total volume of only about 0.04 c.c. A third type were exactly similar except that they were made of soda-glass. They all became exhausted under the discharge with great rapidity, but for the present work the advantage of smaller volume, made possible by the use of platinum electrodes, outweighed the advantage of longer life to be derived from using aluminium electrodes.

Several mixtures of pure helium with pure oxygen, containing only a few parts per million of helium, were made up by the principle of successive dilutions, with the greatest care, using the spectrum-tube filler devised by Sir William Ramsay. With the same device, a known fraction of a cubic centim. of the mixture was admitted to the exhausted calcium furnace. The furnace was sealed off, and a correction applied for the part of the gas not used. The absorption of the oxygen and tilling of the apparatus with mercury were then carried out in the usual manner.

The general result has been to show that with the lead-glass tube described, a quantity of helium below a "tenth-gram," that is $10^{-10}$ gram, cannot be detected; while in a perfect experiment two tenth-grams can be detected with certainty. For the tubes of soda-glass otherwise similar, the quantity detectable is about twice this. In the first place the brightness of the neighbouring sodium lines interferes with the test; and, secondly, the glass conducts much more readily than lead-glass; so that the discharge under some circumstances passes, not through the glass at all, the spectrum of which is not observed, but almost wholly along the glass surface, causing it to fluoresce brilliantly aud show the sodium lines. 'Test C VI. of the table was a very instructive one in this 
respect. On first running the tube the sodium lines were strong and $D_{3}$ scarcely visible, but the character of the discharge suddenly changed and $\mathrm{D}_{3}$ came out more strongly, and continued for some little time quite obvious. The experiments with the old type of tube show the great advantage of reducing the volume; for with these the minimum detectable quantity of helium was about 16 tenth-grams. It was found in actual practice that even when the absorption of the residual gas by the calcium was as perfect as possible, there was no danger of the helium being so pure that it would not conduct the discharge (compare Mackenzie and Soddy, Proc. Roy, Soc. 1908,80 A, p. 92). In order to avoid all doubt from the fact that the electrodes of spectrum-tubes absorb the rare gases, a new spectrum-tube was always used for the actual tests with the radio-elements, and in doubtfui cases in the calibration tests.

In the following Table (p. 528) the calibration experiments have been collected. The first column gives the number of the test $(\mathrm{C}=$ calibration). The second column gives the amount of helium added in "tenth-grams" $\left(10^{-10} \mathrm{gram}\right)$. The third column gives the perfection of the experiment, that is, the degree to which the absorption of the residual gas was complete. If some running of the tube was necessary to clear the spectrum, the test is classed as good, fair, or bad, according to the amount of running required Any experiments in which the spectrum could not be cleared are not included.

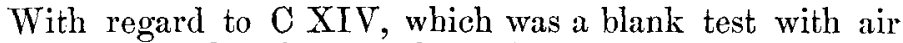
purposely introduced, it was found impossible to mistake any of the lines in the argon spectrum for helium.

Lastly, tests have been made to see what multiple of the minimum quantity of helium detectable by means of the $D_{3}$ line is required to show the bright red line 6677 , and the faint red 7056 . In these experiments the calcium furnace was not filled with mercury. The minimum quantity of helium to show $\mathrm{D}_{3}$ in a small lead-glass spectrum-tube without filling with mercury was found to be about

$$
3 \times 10^{-3} \text { c.c. }\left(=5 \cdot 4 \times 10^{-7} \text { gram }\right) \text {. }
$$

As the ratio of the volume of the whole apparatus to that of the small spectrum-tube was about $1: 2500$, this is in good agreement with the preceding tests. Before any glimpse of the red line 6677 was seen three times this quantity had to be added, while with fonr times the line, though still faint, was obvious. To bring out the faint red line 7056 , at least 20 times the minimum quantity is required; while with 30 times 


\begin{tabular}{|c|c|c|c|c|}
\hline $\begin{array}{l}\text { Number } \\
\text { of Test. }\end{array}$ & $\begin{array}{l}\text { Helimm in } \\
\text { tenth-grms. }\end{array}$ & $\begin{array}{l}\text { Quality of } \\
\text { Experiment. }\end{array}$ & $\begin{array}{l}\text { Observation } \\
\text { of } \mathrm{D}_{3} \text {. }\end{array}$ & Remarks. \\
\hline \multicolumn{5}{|c|}{ Lead-glass spectrum-tubes, $0 \cdot 04$ c.c. volume. } \\
\hline $\mathrm{C} i \ldots$ & 09 & Perfect. & Not seen. & Certainly below limit, \\
\hline C II & 1.8 & Good. & Seen clearly. & Fairly bright argon also. \\
\hline $\mathrm{OXI} \ldots \ldots$ & $1 \cdot 6 \pm$ & Perfect. & Ditto. & $\mathrm{D}_{3}$ less bright than argon \\
\hline $\mathrm{C} \times \mathrm{III} \ldots$ & & & Ditto. & $\mathrm{D}_{3}$ not nuch brighter \\
\hline CXIII ... & 168 & Good. & $\mid \begin{array}{c}\mathrm{D}_{33} \text { the } \\
\text { brightest line. }\end{array}$ & $\begin{array}{l}\text { Exceptionally strong } \\
\text { argon spectrum. }\end{array}$ \\
\hline C XIV & Blank test. & Perfect. & $\begin{array}{c}\text { No line like } \\
\mathrm{D}_{3} .\end{array}$ & 025 c.c. ol air added. \\
\hline \multicolumn{5}{|c|}{ Soda-glass spectrum-tubes, $0 \cdot 04$ c.c. volume. } \\
\hline C III... & $1 \cdot 4$ & Good. & Not seen. & Sodium lines strong. \\
\hline CIV.. & $1 \cdot 8$ & Good. & Seen for a & Sodium lines interfere. \\
\hline $\mathrm{CV}$ & $2 \cdot 2$ & Fair. & Seen for a & Not enough to be \\
\hline $\mathrm{C} V \mathrm{I}$. & 36 & Good. & Seen well. & $\begin{array}{l}\text { But for some time } \mathrm{D}_{3} \\
\text { was hardiy visible. }\end{array}$ \\
\hline \multicolumn{5}{|c|}{ Soda-glass spectrum-tubes, $0 \cdot 3$ c.c. volume. } \\
\hline C VII $\quad \ldots$ & 36 & Bad. & Not seen. & $\begin{array}{l}\text { Strong bydrocarion } \\
\text { spectrum at first. }\end{array}$ \\
\hline C VIII ... & $4 \cdot 1$ & Fair. & Not seen. & Certainly below limit. \\
\hline C IX. & $8 \cdot 2$ & Good. & Not seen. & Ditto. \\
\hline $\mathrm{CX}$ & $16 \cdot 4$ & Gond. & Seen clearly. & About the limit. \\
\hline
\end{tabular}

this line is still excessively faint. The characteristic colour of the helium glow appeared with about 6 times; and the tube began to conduct easily, the spark-gap falling below $2 \mathrm{cms}$. with about 150 times the minimum quantity. In these experiments arrangements were made to admit small quantities of water-vapour when the tube became non-conducting. Then, by making the furnace very hot, the hydrogen of the calcium hydride formed exerts an appreciable tension of dissociation so that the discharge will pass. The degree of vacuum and the amount of hydrogen present did not, within the limits tried, have any appreciable effect on the various quantities 
of helium required to show the different lines. It may be inferred that, so long as a discharge will pass at all, $D_{3}$ will be seen if the minimum quantity of helium is present, however little other gas is present.

It is of interest to compare this quantity of two tenth-grams of helium found to be the minimum quantity detectable by the spectroscope, with the minimum quantity of radium, for example, detectable by radioactive methods. Using the emanation of radium for the test, about $10^{-11} \mathrm{gram}$ is about the smallest detectable quantity, though no doubt with some refinements this could be with certainty reduced. The radioactive method in the case of radium is thus about 20 times more sensitive than the spectroscopic in the case of helium, a comparison much more in favour of the older method than might at first have been anticipated.

\section{Results with Thorium.}

In addition to the calibration tests already described, in all about 30 tests, involving the filling of the apparatus with mercury have been carried out, but only a few of these have been successful, and the results so far obtained are regarded merely as preliminary. Now, however, with greater experience, comparative certainty and immunity from failure have been secured. In the third series of experiments, which remain to be considered, four flasks have been set up, containing thorium nitrate, uranium nitrate, pitchblende in nitric acid solution, and sodium sulphate. The latter is intended partly as a blank experiment. Only the thorium experiment will be detailed in this paper, as the others have not yet been under observation a sufficient period of time.

The flask contains a solution of ordinary commercial thorium nitrate, several years old, corresponding to about 350 grams of the element thorium. The first test was a failure, and the second was rendered ambiguous owing to a trace of mercury entering the spectrum-tube. The third test was carried out successfully after a period of accumulation of 35 days. The absorption of the gas was only moderately perfect, but no indication of $\mathrm{D}_{3}$ was observed at any stage of the experiment. The subsidiary volume $J$ before referred to was not used in this experiment, so that only about one half of the gas would have been obtained for the test. The test therefore indicates that the rate of production of helium from thorium is not greater than $10^{-11}$ (year) ${ }^{-1}$, which is in agreement with the theory given.

In the next test the period of accumulation was 203 days, or about six times the preceding. As before, only about one-half Phil. Mag. S. 6. Vol. 16. No. 94. Oct. 1908. $2 \mathrm{~N}$ 
of the total gas, probably, was obtained for the test. The experiment was a very perfect one, and $D_{3}$ was seen clearly in a fairly strong blue argon spectrum. It was exactly identified with reference to the sodium lines and with a comparison helium tube, and its quantity was estimated to be about 2 tenthgrams. It corresponded very closely with the calibration test C II. This gives for the rate of production of helium from thorium about $2 \times 10^{-12}$ per year.

Further experiments must now be waited for. Not until a consistent series of quantitative tests of this character have been carried out, can any reliance be placed upon the results.

\section{Summary.}

The present rate of production of helium from uranium and thorium indicated by theory is about $2 \times 10^{-12}$ per year as a minimum value if it is produced at all, or about $4.5 \times 10^{-12}$ per year, calculated by an indirect method on the assumption that the $a$-particle is an atom of helium. The first of these values is almost eight times less than the value indicated when these experiments were started three years ago.

The minimum quantity of helium detectable by the spectroscope by the special methods employed has been shown to be two tenth-grams $\left(10^{-10}\right.$ gram), which is somewhat greater than was supposed at the commencement of the work. In consequence, the question has proved more difficult to settle than at first appeared. With the quantities of uranium and thorium employed in these experiments, a period of accumulation of several months is necessary to detect the helium if produced at the theoretical rate.

The experimental difficulties in the way of performing such tests have now been overcome, but only one positive result has so far been obtained. This was with 350 grams of thorium in the form of nitrate. Helium to the extent of about two tenth-grams was detected after a period of accumulation of nearly seven months, which corresponds with a rate of helium production of $2 \times 10^{-12}$ per year. This result is of course of no significance until it is confirmed. All the other tests so far obtained only indicate that the rate of production of helium from both uranium and thorium is certainly below what was first deduced from the imperfect theory, and is certainly not above the rate indicated by the present theoretical data.

Since this paper was written, by the help of a research grant from the Carnegie Trustees, a new series of experiments have been successfully started with quantities of materials five-fold greater than before attempted.

Physical Chemistry Laboratory, Glasgow University. 
SondY.

Phil. Mag. Ser. 6, Vol. 16. Pl, XX.
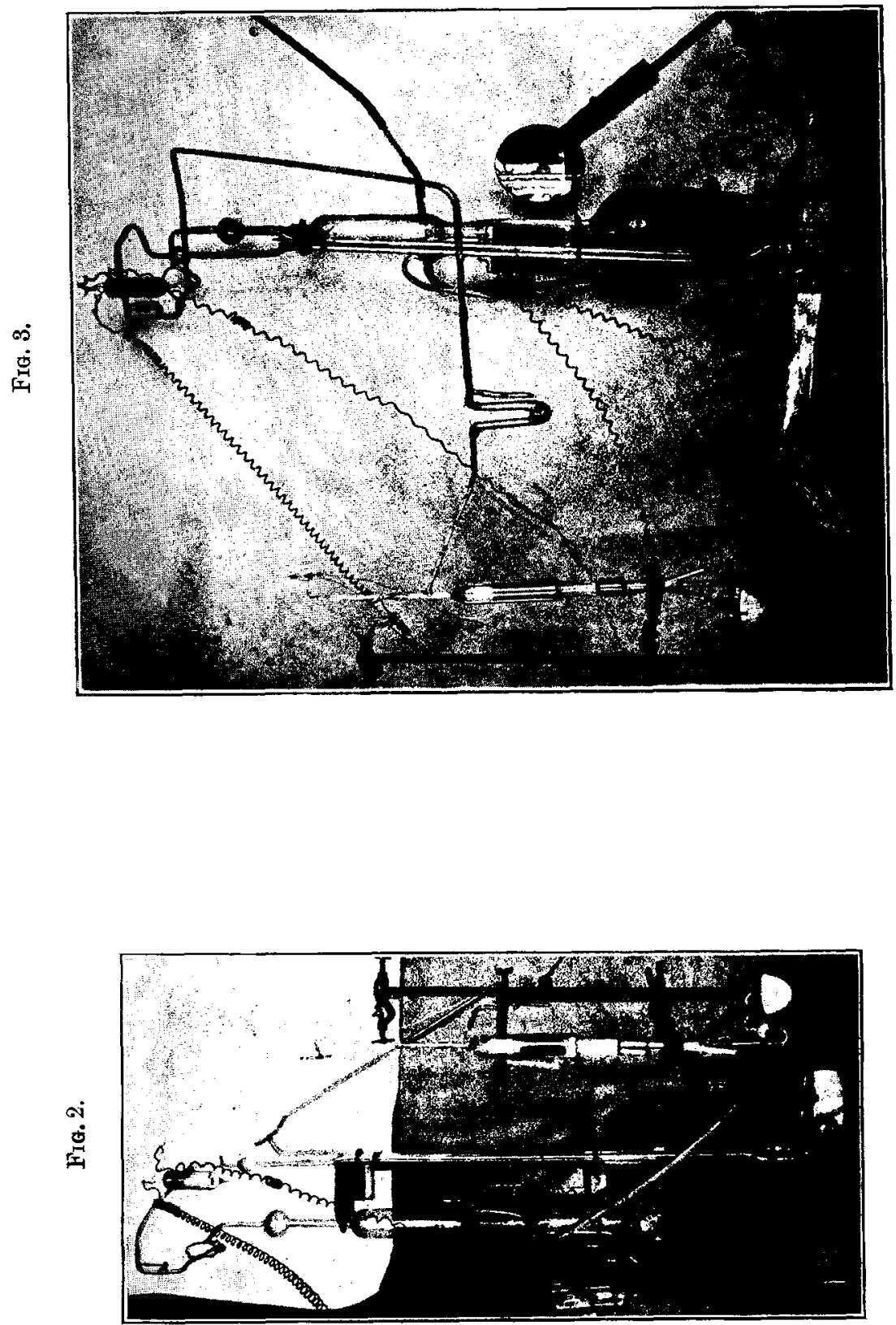